\section{ECONOMICS}

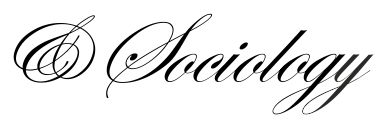

\title{
THE LENGTH OF WORKING LIFE IN RUSSIA: TRENDS AND DIFFERENTIALS
}

\author{
Mikhail Denisenko, \\ National Research University \\ Higher School of Economics, \\ Moscow, Russia, \\ E-mail:mdenissenko@bse.ru \\ Elena Varshavskaya, \\ National Research University \\ Higher School of Economics, \\ Moscow, Russia, \\ E-mail:evarshavskaya@bse.ru
}

Received: February, 2018

1st Revision: March, 2018

Accepted: May, 2018

DOI: $10.14254 / 2071-$

789X.2018/11-2/19
JEL Classification: J22, J21, J11, J26

\begin{abstract}
This article examines the level and the dynamics of working (economically active) life expectancy in Russia, calculated using the Sullivan method. Our results show that the working life expectancy in Russia is shorter than in European and North American countries. This disadvantage is especially evident for the male population. However, Russian males and females also have the shortest periods of economic inactivity, which is predetermined by a short life expectancy. In the context of mass involvement of young adults in the process of obtaining higher education, the estimated retirement period is calculated to be short. A combination of short periods of working life and economic inactivity, along with a low gender-based diversification in terms of working life expectancy distinguishes Russia from other countries. It has been established that high mortality rate at working age determines a considerable part of losses in working life, primarily among the male population of Russia. The potential for growth of the working life expectancy in Russia is strongly related to further reduction of mortality, primarily within major working age groups.
\end{abstract}

Keywords: working life expectancy; economic activity; mortality; retirement age; Russia.

\section{Introduction}

The age structure in Russia, as well as in other countries experiencing a demographic transition, has been drastically and irretrievably changing - the population is ageing too quickly. In the coming 20 years, the proportion of population aged 65 and over will increase from $13.9 \%$ in 2016 to $19.8 \%$ in 2035 , and the share of population over working age is expected to go up from $24.6 \%$ to $29.7 \%$. The overall demographic burden will increase as well - from 749 dependants (per 1000 adults at working age) to 838, therefore, the proportion of elderly people will also increase (Federal State Statistics Service, 2017). In the 21st century, population ageing is a serious challenge for many countries. Major social institutions and systems (healthcare, education, social insurance, pension schemes, labour market etc.), having formed against the background of the previous age structure of population, will be essentially reformed with due regard to new demographic facts. A longer period in labour force is deemed to be one of the options to meet this challenge. For this reason, the majority of EU and OECD member states started increasing the statutory retirement age since the latter 
half of the 1990s, particularly for their female population. Measures have also been put in place in order to limit the opportunities for early retirement and to stimulate later exit from the labour market; requirements to the retirement (insurance) qualifying period have been raised; and certain incentive programs for the elderly people have been developed.

The mainstreaming of issues fuelled by population ageing has heightened researchers' interest in working life expectancy involving such integral indicators as the figures associated with the type of prospective working life expectancy that reflect the characteristics of both economic and demographic processes. Calculations on working life expectancy were first proposed in the United States. During the 1940s-1980s, the US Bureau of Labor Statistics, a unit of the United States Department of Labor, was considered to be a trendsetter in this regard: the Bureau developed a standard method for working life table construction which was later used in other countries and international organisations (Durand, 1948; Fullerton, 1972; Garfinkle, 1963; Smith, 1982; Wolfbein, 1949). Nowadays, studies on working life expectancy have been conducted for the United States (Dudel \& Myrskylä, 2017; Hayward \& Grady, 1990; Millimet et al., 2010, 2003; Skoog \& Ciecka, 2010; Smith, 1986), Finland (Leinonen et al., 2015; Nurminen, 2012; Nurminen et al., 2005), Great Britain (Butt et al., 2008; Haberman \& Bloom, 1990), Netherlands (Liefbroer \& Henkens, 1999), Denmark (Hoem, 1977), Canada (Denton et al., 2010), Spain (Dudel et al., 2018) etc. Since 2014 the working life expectancy has been included into the official reports of the EU Member States as an indicator for analysis and monitoring under the Europe 2020 employment strategy. The Eurostat has been assessing this parameter since 2000 (for details see Eurostat, 2018).

During the 1980s, the issues associated with the duration of working life were also reflected in the works of Soviet researchers (Kruminya, 1985; Milovidov, 1983; Pervushin, 1987). Particularly noteworthy is the research by A. S. Milovidov (1983). Applying data obtained from the population censuses of 1926, 1959 and 1970, he attempted to show the dynamics of certain life cycle stages, including work and the relationships between them as a result of demographic, economic, and social transformations.

In this paper, we present estimates of the length of working life, or of working life expectancy, for Russia from 1992 to 2015 . The year 1992 has been chosen here as the starting point due to the fact that it saw the commencement of Labour Force Surveys, and thus there are proper data associated with labour market status in the context of age and gender. It should be noted that in our research the term "working life" is identified with labour force participation, i.e., with the period of economic activity, and thus includes the periods of both employment and unemployment. Calculations on working life expectancy have been made for the persons who have reached the working age (15 and above), as well as for the elderly people of working age (50 and above). In the first case, we obtained data on the overall duration of the working period within the life cycle of an individual. The duration of working life at 50 reflects opportunities for the elderly people to participate in the labour market and is one of the indicators of the age of exit from the labour market. The length of economic inactivity calculated for this age basically corresponds to the expected duration of retirement. Given that both mortality rate and labour force participation rate show significant differences by gender, calculations in this paper are performed separately for males and females. To the best of our knowledge, these are the first working life expectancy calculations for Russia. We investigated how longevity gains are distributed between the years spent in work, unemployment and activity outside the labour force (economic inactivity). We also decomposed the working life expectancies into the contributions arising from differences in the age-specific mortality rates on the one hand and from labour force participation rates on the other. We conducted a comparative evaluation of the working life expectancy in Russia with similar parameters from other countries and analysed the impact of the mortality rate and economic activity on the countries. In addition, we carried out an assessment of potential 
parameters of the prospective working life expectancy upon the implementation of various forecasts regarding mortality and the rise of retirement age scenarios.

\section{Data and method}

There are two main approaches for the evaluation of working life expectancy: those based on prevalence (cross-sectional data) and those based on incidence (flow data). In labour market studies, the prevalence-based method draws on the percentages of people belonging to the labour force and employed people, i.e. labour market resource information, at a given time. By contrast, the incidence-based method uses the probability of transition from one labour market status to another, e.g. transitions into the labour force or transitions out of the labour force. It is carried out through multiple-decrement tables or multi-status tables of labour activity, while data acquisition involves longitudinal surveys or the availability of population registers.

In the case of measuring working life expectancy for a calendar period, each of these life table-based methods has an artificial starting point, i.e. a synthetic cohort, to which the prevalences or incidences of the year being studied are applied in each one-year age group. For instance, in calculating the expected period for belonging to the labour force, the prevalence-based method gives an expectancy figure which describes for each specific age $\mathrm{x}$ the expected average period of belonging to the labour force after attaining age $\mathrm{x}$ if the mortality and activity rates for the year being studied apply. Meanwhile, the incidence-based method describes the expected periods that the cohort will spend as part of the labour force and outside the labour force, assuming that the mortality and probability of transition in and out of the labour force for the year being studied apply (Hytti \& Nio, 2004).

The method of observed prevalence (also called the Sullivan method ${ }^{1}$ ) was used in this article in order to evaluate the working life expectancy (Sullivan, 1971). The Sullivan method combines standard period life tables and period information on labour market distributions by single years of age. The choice of this method is conditioned by the availability of data and their cross-sectional nature. It is important to note such advantages of the Sullivan method as clear interpretation, tolerance to random perturbations caused, among other things, by data quality, and independence from the age structure of the population. All this ensures comparability of calculations by country, as well as by certain social and demographic groups (Vogler-Ludwig, 2009). According to a comparative analysis, there are no significant variations between the working life expectancy evaluation data obtained through the Sullivan method and through multi-status tables (Schoen \& Woodrow, 1980; Nurminen, 2012). So this robust methodology is used quite often especially in the comparative analysis by countries and social groups (e.g., Leinonen et al., 2015; Loichinger \& Weber, 2016; Vogler-Ludwig, 2009).

The research involved the use of the decomposition method suggested by S. Preston et $a l$. in order to evaluate the impact of mortality and economic activity rates on the dynamics of the working life expectancy in Russia, as well as on the intercountry differences of this parameter (Preston et al., 2001).

The essential 'ingredients' for calculating the working life expectancy are life tables and labour force participation rates. The data used in this study originate from two main sources: (a) the Russian Labour Force Survey and (b) the Human Mortality Database (HMD, 2017). Labour force participation rates by age and gender are based on the Russian Labour

\footnotetext{
${ }^{1}$ In 1971, D. Sullivan first applied this method to calculate the expected healthy life expectancy. But, in reality, this method was proposed for the first time in 1948 by D. Durand precisely for calculating the duration of working life (Durand, 1948). Therefore, the method of Sullivan can be called the method of Durand-Sullivan (see Cambois et al., 1999), Skoog \& Ciecka (2016) for an overview of the evolution of working life expectancy methods).
} 
Force Survey. This research is conducted by the Federal State Statistics Service using the international methodology with due regard to the standard definitions of labour force, employment and unemployment according to the International Labour Organization recommendations.

\section{Working life expectancy dynamics in Russia (1992-2015)}

The working life expectancy dynamics at age 15 in Russia may be divided into two periods (Graph 1). The first period includes its fall during the 1990s. During this period, the working life expectancy experienced double pressure - reduction in the overall life expectancy and a transformational economic crisis resulting in reduction in labour demand. As a consequence, during the period from 1992 to 2002, the working life expectancy in Russia at age 15-72 decreased by 4.3 years (from 35.2 to 30.9) for males, and by 2.6 years (from 33.9 to 31.3 ) for females ${ }^{2}$. The second period that began in 2003 is characterised by a gradual increase in the working life expectancy at age 15, being more significant for males than for females. By 2015, it had increased by 3 years (33.8) for males, and by just 0.8 (32.1) for females. Notably, the overall increase for females is related to the mid-2000s, while stagnation has been observed since 2007. Until recently, the expected duration of working life had not reached the level of the 1990s, while the increase, in fact, is still of a recovering nature.

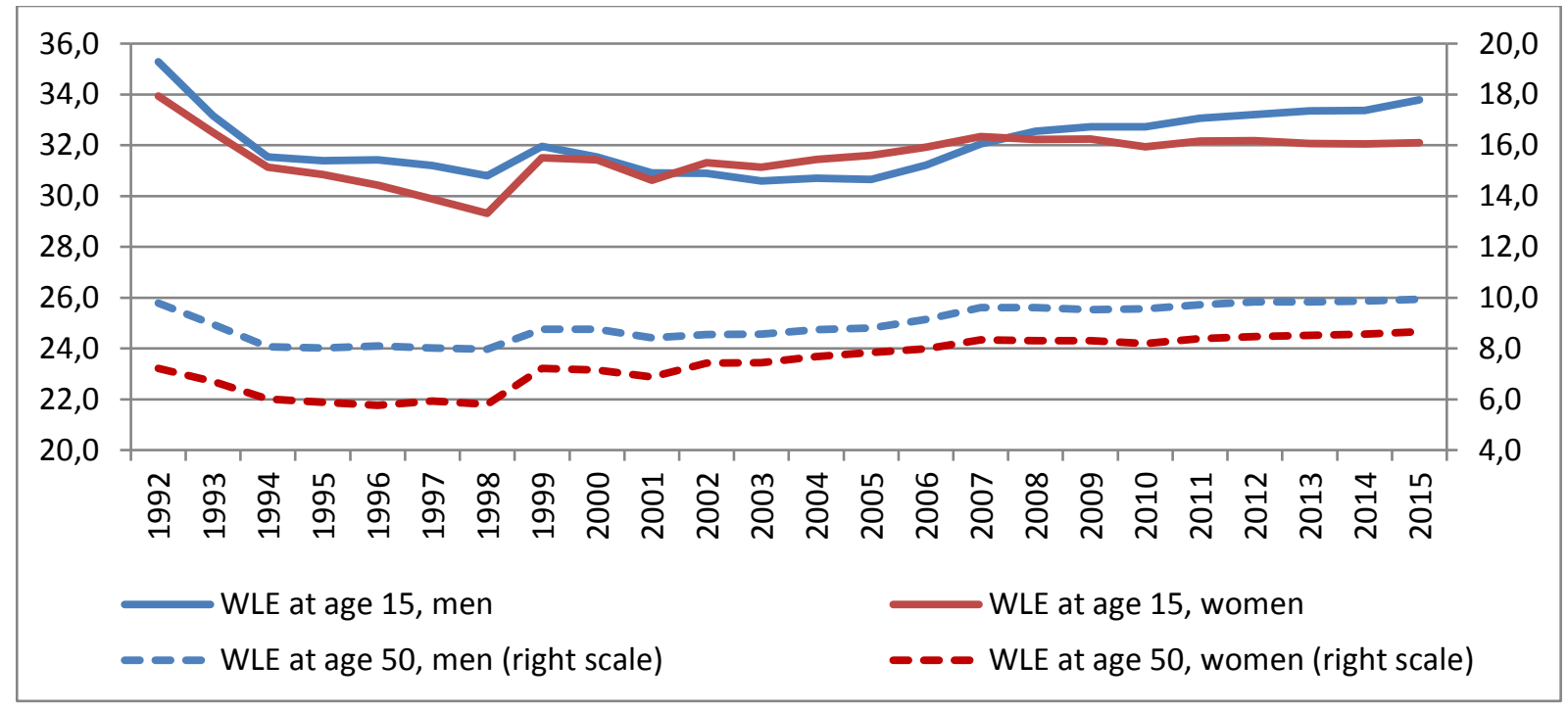

Graph 1. Working life expectancy (WLE) at age 15 and at age 50, men and women, 19922015 , in years

Source: authors' calculations.

Graph 2 presents our calculations for working life expectancy spent in different labour market statuses (employment, unemployment, and economic activity) by sex between 1992 and 2015. During the 1990s crisis, the duration of working life for both males and females decreased dramatically by about 7 years (or by 20\%). The expected duration of unemployment was twice as long. Since the early 2000s, there has been an upward trend with regard to the employment expectancy and reduction of unemployment for males and females.

\footnotetext{
${ }^{2}$ The volatility of the estimates of the expected duration of working live in the late 1990s - early 2000s largely depends on the changing of identification rules for certain groups of the population according to their labour market status.
} 
The exception is provided by the critical 2009-2010 period, when the expected duration of employment decreased, while unemployment increased. As opposed to the above parameters, the dynamics of the duration of economic inactivity are associated with status of economic life to a lesser extent. We observe the growth of this parameter during the critical 1990s as well as starting from the mid-2000s, i.e. during a satisfactory period in economic terms. During the 1990s, the expected duration of economic inactivity increased for both genders. A more sophisticated analysis shows that this increase primarily depended on young adults and their high demand for professional education, as well as on the turning of a certain proportion of the population towards household production, which was disregarded in making an assessment of the economic activity. These processes came against the background of an overall life expectancy reduction. By contrast with the 1990s, the growth of the duration of economic inactivity during the latest decade (2005-2015) comes against the background of derating of people's non-participation in the labour force and is caused by an increase in overall life expectancy.
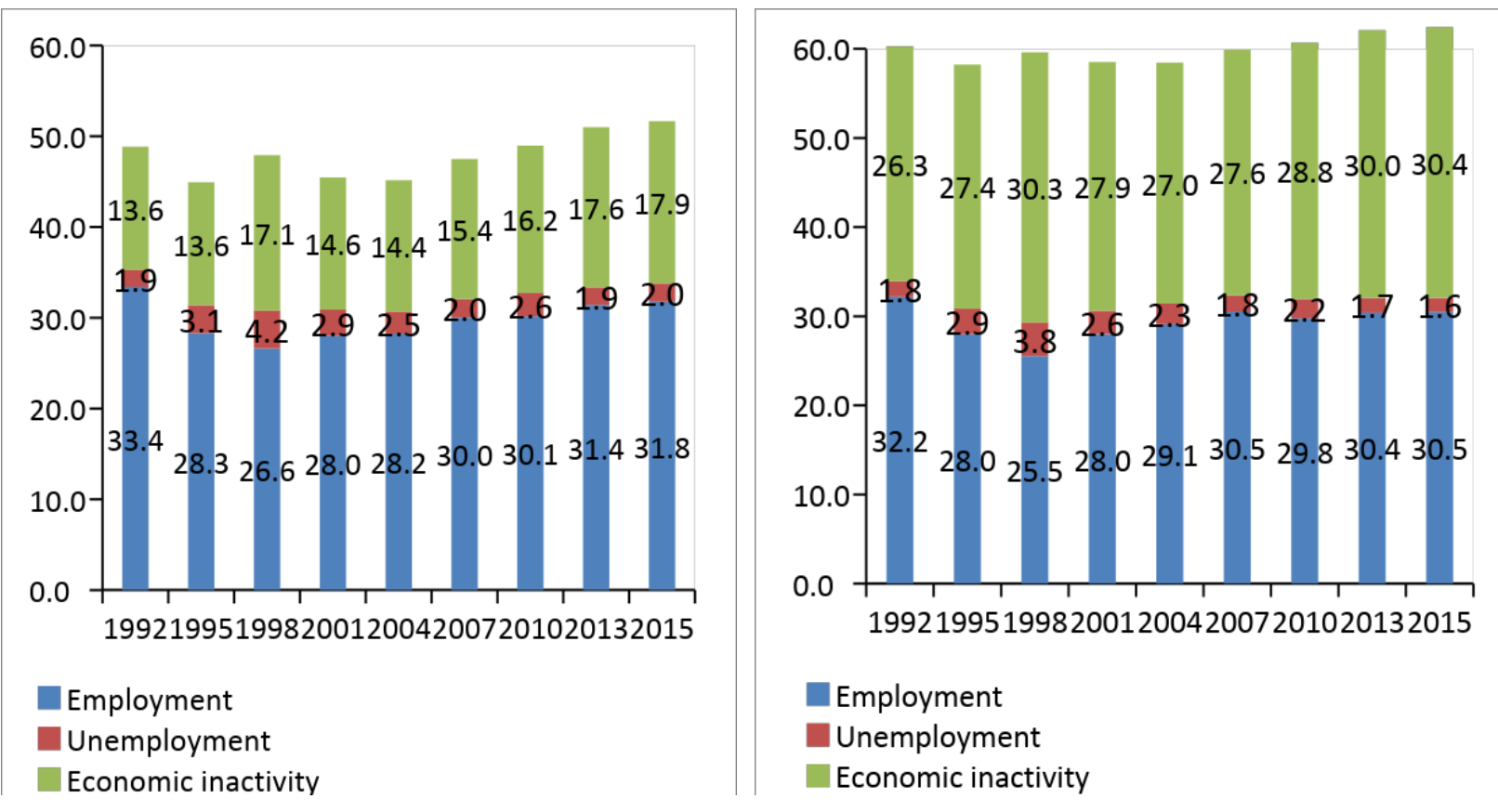

Graph 2. Total life expectancy at age 15 (above the bars), divided into years spent in different labour market statuses (beside the bars) by sex in selected calendar years (men - right scale, women - left scale)

Source: authors' calculations.

The working life expectancy dynamics at age 50 mostly repeated the dynamics at age 15: a decrease during the early 1990s, stagnation in the latter half of the 1990s, and a slow growth during the 2000-2010s. These processes occurred at the same pace for elderly males and females $(\text { Graph } 1)^{3}$. The calculations performed show that the indicative age of exit from the labour market in the late 1990s was 58-59 years for Russian males, and 56 years for females. By the mid-2010s, this parameter increased up to 60 years in respect of males and

\footnotetext{
${ }^{3}$ It should be noted that the working life expectancy dynamics at age 15 and at age 50 in Russia differ from the same dynamics in various European and North American countries. In these countries, the growth of the working life expectancy started in the latter half of the 1990s for males, and from the mid-1960s for females (Loichinger \& Weber, 2016).
} 
58-59 in respect of females ${ }^{4}$. The period of economic inactivity at age 50, i.e. the anticipated duration of the retirement period, lowered during the period from 1992 to 2002 . The reduction was 1.2 years for males (from 9.8 to 8.6 ) and 1.7 for females (from 20.5 to 18.8). A smooth growth of this parameter started from 2003 and by 2015 it increased by 3.2 years for males and by 2.5 years for females.

Russia is characterised by a low gender difference in terms of the working life expectancy. The working life expectancy at age 15 is less than one-and-a-half years longer among men than among women. Moreover, there was a unique case from 2002-2007: the working life expectancy of Russian females aged 15 exceeded the working life expectancy of males by 0.3-0.9 years, despite the higher economic activity of the latter. This phenomenon stems from the fact that the mortality rate at working age increased more noticeably for males as compared to females, while on the other hand the economic activity level decreased more noticeably for males as compared to females. At age 50, the gender gap was over two years in the 1990s, then during 2000-2015 it shortened by almost half to 1.1-1.3 years. In contrast, the gender difference in the duration of economically inactive life is significant, which is the result of a substantial difference in the working life expectancy of males and females. Russian females spent much more time out of the labour market than males: the disparity between the expected duration of economically inactive life at age 15 is about 13 years, and at age 50 is about 9 years, and it remains practically the same during the investigated period.

The working life expectancy dynamics are determined by the change of mortality rates and labour force participation. Table 1 shows the impact of the mortality and economic activity rate on the working life expectancy dynamics in Russia. The decrease between 1992 and 2002 was mainly attributable to the decrease in the labour force participation rate. This factor explains $80 \%$ of the decreases in the working life expectancy for females and $63 \%$ for males. By contrast, the increase in the working life expectancy from 2002-2015 derived mainly from a reduction of mortality. This factor determines almost $85 \%$ of growth in working life expectancy for males and $75 \%$ for females. Russia's differential characteristic is the dependence of growth in working life expectancy on the reduction of mortality. In other countries, this factor is primarily determined by increase in economic activity, in particular among females (Leinonen et al., 2015; Loichinger \& Weber, 2016). The insignificant impact of mortality on working life expectancy in the majority of European and North American countries is determined by its low rate, particularly at working ages, which had already been achieved by the 1970s. With all the positive trends of the latest 10-12 years, the mortality rate is still significantly high in Russia.

Table 1. Decomposition of the difference in the working life expectancy at age 15-72

\begin{tabular}{lcccc}
\hline & \multirow{2}{*}{ Years } & \multirow{2}{*}{\begin{tabular}{c} 
Total difference in \\
the working life \\
\cline { 4 - 5 }
\end{tabular}} & & \multicolumn{2}{c}{$\begin{array}{c}\text { Components contributing to } \\
\text { expectancy, years }\end{array}$} & Mortality rate & $\begin{array}{c}\text { Labour force } \\
\text { participation rate }\end{array}$ \\
\hline \multirow{2}{*}{ Men } & $1992-2002$ & -4.3 & -1.6 & -2.7 \\
\hline \multirow{2}{*}{ Women } & $2002-2015$ & 2.9 & 2.5 & 0.4 \\
\cline { 2 - 5 } & $1992-2002$ & -2.6 & -0.5 & -2.1 \\
\hline
\end{tabular}

Source: authors' calculations.

\footnotetext{
${ }^{4}$ The statutory retirement age in Russia is 60 years for males, and 55 for females.
} 


\section{Russia versus other countries (international comparison)}

The working life expectancy of Russian men at age 15 in 2015 was the shortest among the investigated countries, i.e. 33.8 years (Table 2). It is a quarter (or 11.4 years) less than in Japan, which is the leader. Russian men were expected to spend two-thirds (65.4\%) of their total life expectancy in the labour market. Only the Japanese spent more time in the labour force $(68.4 \%)$. Stated otherwise, men in other investigated countries work longer than Russians in terms of the expected absolute number of years but less in relative size, i.e. as the share of the total life expectancy spent in the labour market. The expected duration of economic inactivity of Russian men at the age of 15 was also the shortest (17.9 years). It is 12.4 years less than Italians who have the longest duration of economic inactivity (30.3 years). Russia's last place with reference to these two factors is determined by a relatively short total life expectancy.

Table 2. Working and economic inactive life expectancy at age 15 and at age 50, men, 2015*

\begin{tabular}{|c|c|c|c|c|c|c|c|c|}
\hline & \multicolumn{4}{|c|}{ Life expectancy at age 15} & \multicolumn{4}{|c|}{ Life expectancy at age 50} \\
\hline & total & working & $\begin{array}{l}\text { econo- } \\
\text { mic } \\
\text { inactive }\end{array}$ & $\begin{array}{c}\text { share } \\
\text { WLE } \\
\text { in LE, \% }\end{array}$ & total & working & $\begin{array}{l}\text { econo- } \\
\text { mic } \\
\text { inactive }\end{array}$ & $\begin{array}{c}\text { share } \\
\text { WLE } \\
\text { in LE, \% }\end{array}$ \\
\hline RUSSIA & 51.7 & 33.8 & 17.9 & 65.4 & 22.6 & 9,9 & 12,7 & 43,8 \\
\hline Lithuania & 53.7 & 34.7 & 19.0 & 64.6 & 22.7 & 11,1 & 11,6 & 48,9 \\
\hline Hungary & 57.9 & 35.0 & 22.9 & 60.5 & 24.7 & 9.6 & 15.1 & 38.7 \\
\hline Poland & 59.1 & 35.2 & 23.9 & 59.5 & 26.8 & 7.7 & 19.1 & 28.8 \\
\hline Italy & 65.8 & 35.6 & 30.3 & 54.0 & 32.2 & 11.5 & 20.7 & 35.6 \\
\hline Latvia & 55.1 & 35.8 & 19.2 & 65.0 & 23.7 & 10.9 & 12.8 & 46.0 \\
\hline France & 64.8 & 36.6 & 28.2 & 56.4 & 31.7 & 10.0 & 21.7 & 31.7 \\
\hline Spain & 65.4 & 37.4 & 28.0 & 57.2 & 31.6 & 11.0 & 20.6 & 34.7 \\
\hline Estonia & 58.0 & 37.7 & 20.3 & 64.9 & 26.2 & 11.9 & 14.3 & 46.7 \\
\hline Finland & 63.6 & 38.2 & 25.4 & 60.1 & 30.5 & 11.4 & 19.1 & 37.4 \\
\hline Czech & 61.3 & 38.2 & 23.1 & 62.4 & 28.0 & 12.0 & 16.0 & 42.9 \\
\hline Portugal & 63.5 & 38.7 & 24.8 & 60.9 & 30.3 & 13.1 & 17.2 & 43.5 \\
\hline Ireland & 64.8 & 39.2 & 25.6 & 60.5 & 31.5 & 13.6 & 17.9 & 43.2 \\
\hline USA & 62.6 & 40.0 & 22.6 & 63.9 & 30.2 & 13.8 & 16.4 & 45.8 \\
\hline Germany & 63.7 & 40.2 & 23.5 & 63.1 & 30.1 & 12.9 & 17.2 & 42.7 \\
\hline Norway & 65.7 & 41.0 & 24.7 & 62.5 & 31.9 & 13.8 & 18.1 & 43.2 \\
\hline $\begin{array}{l}\text { United } \\
\text { Kingdom }\end{array}$ & 64.8 & 41.4 & 23.4 & 63.8 & 31.4 & 13.1 & 18.3 & 41.8 \\
\hline Sweden & 65.7 & 41.9 & 23.8 & 63.9 & 32.0 & 14.2 & 17.8 & 44.5 \\
\hline Canada & 65.7 & 42.2 & 23.5 & 64.3 & 31.9 & 13.7 & 18.2 & 43.0 \\
\hline Netherlands & 65.4 & 42.8 & 22.6 & 65.4 & 31.5 & 13.5 & 18.0 & 42.8 \\
\hline Japan & 66.1 & 45.2 & 20.9 & 68.4 & 32.4 & 17.9 & 14.5 & 55.4 \\
\hline
\end{tabular}

* The countries are sorted according to the increase of working life expectancy at age 15 .

Source: authors' calculations.

The expected duration of the working life of Russian women stood at 32.1 years in 2015 (Table 3). This is 6.3 years more than Italian women who have the shortest working life expectancy (25.8 years), and 7.9 years less than Swedish women who have the longest 
working life expectancy (40.0 years). Russian women have one of the shortest durations of economic inactivity (30.4) trailing only (about 1 year) Latvian, Lithuanian, and Swedish women. As for men, the place of Russia among other countries is determined by the lag in the total life expectancy. In the early 1990s, the working life expectancy of Russian women was one of the highest (about 34 years). In 1992, Russia was ranked next to Norway (34.6 years) and was second only to Sweden (38.7 years). Unlike females, in the early 1990s the Russian men were behind the developed countries in the working life expectancy to a significant degree (for 4-5 years), except for the countries of Central and Eastern Europe, and France. Over the two decades, the lag in the working life expectancy of Russian men has increased, while Russian women have ceased to be leaders in this indicator, skipping ahead of the residents of 15 countries.

Table 3. Working and economic inactive life expectancy at age 15 and at age 50, women, $2015^{*}$

\begin{tabular}{lcccccccc}
\hline & \multicolumn{3}{c}{ Life expectancy at age 15 } & \multicolumn{3}{c}{ Life expectancy at age 50 } \\
\cline { 2 - 10 } & total & working & $\begin{array}{c}\text { econo- } \\
\text { mic } \\
\text { inactive }\end{array}$ & $\begin{array}{c}\text { share } \\
\text { WLE } \\
\text { in LE, } \%\end{array}$ & total & working & $\begin{array}{c}\text { econo- } \\
\text { mic } \\
\text { inactive }\end{array}$ & $\begin{array}{c}\text { WLE } \\
\text { in LE, \% }\end{array}$ \\
\hline Italy & 70.1 & 25.8 & 44.3 & 36.8 & 35.9 & 7.2 & 28.7 & 20.1 \\
\hline Poland & 66.8 & 30.0 & 36.8 & 44.9 & 32.8 & 7.7 & 25.1 & 23.5 \\
\hline Hungary & 64.6 & 30.0 & 34.6 & 46.4 & 30.7 & 8.3 & 22.4 & 27.0 \\
\hline Ireland & 68.8 & 30.9 & 37.9 & 44.9 & 34.7 & 9.1 & 25.6 & 26.3 \\
\hline Czech & 67.0 & 31.9 & 35.1 & 47.7 & 32.9 & 10.0 & 22.9 & 30.4 \\
\hline RUSSIA & 62.5 & 32.1 & 30.4 & 51.4 & 30.0 & 8.7 & 21.3 & 28.9 \\
\hline Spain & 71.1 & 32.7 & 38.4 & 46.0 & 36.7 & 8.6 & 28.1 & 23.6 \\
\hline France & 70.8 & 33.0 & 37.8 & 46.6 & 36.7 & 9.2 & 27.5 & 25.1 \\
\hline USA & 67.1 & 34.5 & 32.6 & 51.4 & 33.7 & 11.6 & 22.1 & 34.4 \\
\hline Latvia & 64.8 & 35.0 & 29.8 & 54.0 & 31.3 & 11.2 & 20.1 & 35.8 \\
\hline Portugal & 69.3 & 35.0 & 34.3 & 50.5 & 35.2 & 10.0 & 25.2 & 28.6 \\
\hline Lithuania & 64.6 & 35.2 & 29.4 & 54.5 & 31.2 & 11.1 & 20.1 & 35.6 \\
\hline Japan & 72.3 & 35.5 & 36.8 & 49.1 & 38.1 & 12.8 & 25.3 & 33.6 \\
\hline Germany & 68.5 & 35.8 & 32.7 & 52.3 & 34.3 & 11.1 & 23.2 & 32.2 \\
\hline United & 68.4 & 36.1 & 32.3 & 52.9 & 34.3 & 10.7 & 23.6 & 31.2 \\
\hline Kingdom & 67.3 & 36.3 & 31.0 & 54.0 & 33.5 & 13.1 & 20.4 & 39.1 \\
\hline Estonia & 69.0 & 37.0 & 32.0 & 53.6 & 35.0 & 11.6 & 23.4 & 33.1 \\
\hline Finland & 69.0 & 37.3 & 31.7 & 54.1 & 34.7 & 9.9 & 24.8 & 28.5 \\
\hline Netherlands & 69.5 & 37.7 & 31.8 & 54.2 & 35.5 & 11.3 & 24.2 & 31.7 \\
\hline Canada & 69.4 & 38.5 & 30.9 & 55.5 & 35.1 & 12.1 & 23.0 & 34.4 \\
\hline Norway & 69.3 & 40.0 & 29.3 & 57.7 & 35.0 & 12.8 & 22.2 & 36.6 \\
\hline Sweden & 69.3 &
\end{tabular}

* The countries are sorted according to the increase of working life expectancy at age 15 .

Source: authors' calculations.

The working life expectancy of Russian men at age 50 is relatively short -9.9 years. With respect to the expected absolute number of years in the labour market, Russia is approaching the lower limits of average. This is roughly the same as the figure for men in Poland, Hungary and France. Russian men who have reached age 50 still spend 12.7 years 
outside the labour market. The expected duration of economic inactivity is one of the shortest as well. The same values are observed among males in Lithuania and Latvia where the retirement age is being raised. As for Russian females, their position is roughly the same. The working life expectancy of Russian women at age 50 is close to the lower limits of the average ( 8.7 years). At the same time (together with the female residents of the Baltic countries), they have the shortest duration of economic inactivity (21.3 years). In many countries, a short working life expectancy is combined with a long duration of economic inactivity, as for both males and females of Italy, Spain, France and Poland. Russia's position is unique in several ways. In our country, as well as in some of the post-socialist countries (for example, in Hungary), short periods of working life and economic inactivity have been observed. This is due to a short overall life expectancy.

Our results suggest that in international comparison, the working life expectancy of Russian men is very short, while with respect to Russian women, it is close to the lower limits of the average values. At the same time, Russian males and females have the shortest duration of economic inactivity, which is determined by a short life expectancy. A combination of the short working life and economic inactivity along with low gender differences in the working life expectancy and a significant gap in the duration of economic inactivity distinguishes Russia from other countries.

In Table 4, the differences in working life expectancy among Russia and some other countries (Japan, the USA, Sweden) are decomposed into the contributions arising from differences in the mortality rates on the one hand and the labour force participation rates on the other. The high mortality rate at the working age determines a significant part of losses in working life, first of the entire male population of Russia. The contribution of this factor explains $68 \%$ of the lag of the Russian male working life expectancy from the American, $57 \%$ from the Swedish, and 52\% from the Japanese counterparts.

Table 4. Decomposition of the difference in the working life expectancy at age 15-69, 2015

\begin{tabular}{lccc}
\hline & $\begin{array}{c}\text { Total difference } \\
\text { in the working life } \\
\text { expectancy, years }\end{array}$ & to the difference in the working life expectancy, years \\
\cline { 3 - 4 } & & Mortality rate & $\begin{array}{c}\text { Labour force } \\
\text { participation rate }\end{array}$ \\
\hline Japan-Russia & 9.0 & 4.7 & 4.3 \\
\hline Men & 1.9 & 1.2 & 0.7 \\
\hline Women & & & 3.3 \\
\hline Sweden-Russia & 7.6 & 4.3 & 6.6 \\
\hline Men & 7.8 & 1.2 & 1.5 \\
\hline Women & & & 0.7 \\
\hline USA - Russia & 4.7 & 3.2 & \\
\hline Men & 1.4 & 0.7 & \\
\hline Women & & &
\end{tabular}

Source: authors' calculations.

\section{Rise of retirement age and working life expectancy}

The raising of the retirement age has led to heated discussions within the Russian academic and expert community. Economists (Kudrin, Gurvich, 2012) and experts from international organisations (World Bank, 2015; OECD, 2013) consider the raising of the retirement age to be the way to solve problems of sustainability of the financial and social protection systems and address the decline of population at the working age. According to 
demographers, there is no reasonable basis for the rise of the retirement age in Russia (Vishnevsky et al., 2012). The major cause is a short life expectancy by today's standards and the poor state of health of the Russian population. However, beyond our vision is the following question: how will a possible raising of the retirement age affect the life cycle of Russian citizens, and the expected duration of working life and economic inactivity? Calculations of the working and economic inactive life expectancy were made on three variants of life expectancy projection carried out by the Institute of Demography of the National Research University Higher School of Economics in 2016, and three scenarios of the raising of the retirement age by the Economic Expert Group (Ivanova et al., 2017).

According to the low variant, by 2030, male life expectancy at birth will increase up to 67.4 years and for females, up to 77.7; the medium variant shows 70.4 and 76.4 years, respectively; the high -73.5 years for males, and 81.1 years for females ${ }^{5}$. The high variant refers to a relatively rapid growth of life expectancy similar to the growth in the Eastern European countries after the crisis of the 1990s. The raising of the retirement age scenarios is stipulated as follows: the first (baseline) scenario - annual increase by six months until 65 for men and women; the second (hard) - annual increase by one year until 65 for men and women; the third (soft) - annual increase by six months until 63 for men, and 62 for women. However, it is expected that the labour force participation rate increases in older age groups (55-64 years for females, and 60-64 for males), while for the other age groups it remains unchanged.

Table 5 presents calculations for the expected duration of working life and economic inactivity at age 15 and at age 50 by variants of projection. Without reducing the mortality rate, the increase in the working life expectancy on the low variant of the life expectancy projection is achieved as a result of the redistribution of life time due to its inactive part. In this case, the growth in the duration of working life for men is small: 1.0-1.3 years at age 15 and about 1 year at age 50. The increase in women's duration of working life is higher: 2.32.5 years at age 15 and about 2 years at age 50 . In general, Russia's position among other developed countries does not change. However, the expected duration of economic inactivity is being reduced for both males and females. The raising of the retirement age with a relatively rapid decrease of mortality rate (the high variant of life expectancy projection) has a significant effect on the increase in working life expectancy: for men at age 15 - about 3.5 years, for women - about three years. The duration of the economic inactivity period will increase as well.

Table 5. Working and economic inactive life expectancy at age 15 and at age 50 by variants of projection

\begin{tabular}{|c|c|c|c|c|c|c|c|c|}
\hline \multirow{2}{*}{$\begin{array}{l}\text { Scenarios of } \\
\text { retirement } \\
\text { age } \\
\text { rising }\end{array}$} & \multirow{2}{*}{$\begin{array}{l}\text { Variants of } \\
\text { life } \\
\text { expectancy } \\
\text { projection }\end{array}$} & \multirow{2}{*}{$\begin{array}{c}\text { Retirement } \\
\text { age will be } \\
\text { reached } \\
\text { by... }\end{array}$} & \multicolumn{3}{|c|}{$\begin{array}{c}\text { Life expectancy } \\
\text { at age } 15\end{array}$} & \multicolumn{3}{|c|}{$\begin{array}{c}\text { Life expectancy } \\
\text { at age } 50\end{array}$} \\
\hline & & & total & working & $\begin{array}{l}\text { econo- } \\
\text { mic } \\
\text { inactive }\end{array}$ & total & working & $\begin{array}{l}\text { econo- } \\
\text { mic } \\
\text { inactive }\end{array}$ \\
\hline 1 & 2 & 3 & 4 & 5 & 6 & 7 & 8 & 9 \\
\hline$M e n$, in 2015 & & & 51.7 & 33.8 & 17.9 & 22.6 & 9.9 & 12.7 \\
\hline \multirow{3}{*}{ Baseline } & low & 2027 & 52.4 & 35.2 & 17.2 & 23.2 & 11.2 & 12.0 \\
\hline & medium & 2027 & 55.2 & 36.3 & 18.9 & 24.5 & 11.5 & 13.0 \\
\hline & high & 2027 & 57.8 & 37.5 & 20.3 & 25.6 & 11.8 & 13.8 \\
\hline
\end{tabular}

\footnotetext{
${ }^{5}$ According to Rosstat estimates, in 2015 (base year of projection) life expectancy at birth in Russia was equal to 65.9 years for males, and 76.7 years for females.
} 


\begin{tabular}{lllllllll}
\hline \multicolumn{1}{c}{$l$} & \multicolumn{1}{c}{2} & 3 & 4 & 5 & 6 & 7 & 8 & 9 \\
\hline \multirow{3}{*}{ Hard } & low & 2022 & 52.0 & 34.9 & 17.1 & 22.8 & 11.1 & 11.7 \\
\cline { 2 - 8 } & medium & 2022 & 53.9 & 35.7 & 18.2 & 23.8 & 11.3 & 12.5 \\
\cline { 2 - 8 } & high & 2022 & 55.9 & 36.6 & 19.3 & 24.8 & 11.6 & 13.2 \\
\hline \multirow{3}{*}{ Soft } & low & 2025 & 52.4 & 35.1 & 17.4 & 23.1 & 11.2 & 11.9 \\
\cline { 2 - 8 } & medium & 2025 & 54.8 & 36.1 & 18.6 & 24.2 & 11.4 & 12.8 \\
\cline { 2 - 8 } Women, in & high & 2025 & 57.1 & 37.2 & 19.9 & 25.3 & 11.7 & 13.6 \\
\hline \multirow{3}{*}{ Baseline } & low & 2037 & 63.5 & 32.1 & 30.4 & 30.0 & 8.7 & 21.3 \\
\cline { 2 - 8 } & medium & 2037 & 65.5 & 35.0 & 30.4 & 31.6 & 10.9 & 20.7 \\
\hline \multirow{3}{*}{ Hard } & high & 2037 & 67.1 & 35.4 & 31.7 & 32.7 & 11.0 & 21.7 \\
\cline { 2 - 8 } & low & 2027 & 63.0 & 34.4 & 28.6 & 30.2 & 10.8 & 19.4 \\
\hline \multirow{3}{*}{ Soft } & medium & 2027 & 64.5 & 34.7 & 29.7 & 31.1 & 10.8 & 20.2 \\
\cline { 2 - 8 } & high & 2027 & 65.9 & 35.2 & 30.7 & 31.8 & 10.9 & 20.9 \\
\hline & low & 2033 & 63.5 & 34.5 & 29.0 & 30.5 & 10.8 & 19.7 \\
\cline { 2 - 8 } & medium & 2033 & 65.1 & 34.9 & 30.2 & 31.4 & 10.9 & 20.5 \\
\cline { 2 - 8 } & high & 2033 & 66.7 & 35.3 & 31.3 & 32.4 & 11.0 & 21.4 \\
\hline
\end{tabular}

Source: authors' calculations.

\section{Conclusion}

Working life expectancy measures the number of years for which a person at a given age is expected to be active in the labour market, and reflects both the demographic (mortality rate) and economic (labour force participation) characteristics of the labour force. The indicator allows an estimation of the age specifics of lifetime distribution, the degree of usage of the working period, labour potential losses as a result of the joint influence of the economic and demographic factors, and the influence of these factors on the size and dynamics of the expected duration of active economic life. Another equally important aspect of interpretation arises from the comparison of the working life expectancy and the overall life expectancy. In this case, the focus of the analysis turns from the length of working life to the entire life cycle and the relationship between different phases (especially those such as employment and economic inactivity). This makes it possible to rate the working period in a person's life cycle and to specify the duration of economic inactivity which is associated with significant functions such as education and training, parenting, care for family members, health care, and recreation.

Our results indicate that in an international comparison with the countries of Europe and North America, Russian working life expectancy levels are relatively short. The lag is particularly high for the male population. Despite the growth of the working life expectancy in the last decade, the backlog is not declining. In economic terms, a shorter working life period means a smaller number of manufactured products, a lower amount of aggregate individual income, and a shorter period of payment of insurance contributions to pension funds. On the other hand, the Russian population is defined by a short length of economic inactivity. In the context of delayed entry into the labour market (because of the increased involvement of youth in the process of higher education), the duration of economic inactivity of Russian citizens is primarily limited from the above; speaking otherwise, the short period is the period after exit from the labour market, i.e. the expected retirement period.

When we looked at trends, we found that the working life expectancy of Russians decreased significantly during the 1990s. The decrease in working life expectancy was mainly driven by the decrease in labour force participation rates. Since the early 2000s, the length of working life began to increase. However, this growth has a recovering nature. Unlike the 
decrease in the working life expectancy, the increase of this parameter is primarily determined by a reduction of mortality. Despite the positive trends of the last 10-12 years, Russia is still defined by high mortality rates at working age, particularly as regards the male population. Our estimates indicate that the high mortality determines a significant part of losses in the working life expectancy and Russia's lag as compared to other countries. Thereby, the potential for growth of the working life expectancy in Russia is primarily related to a reduction of mortality.

Given our findings, the raising of the retirement age should be conformed to the growth of the life expectancy and to design effective policies that encourage a productive prolongation of working life, without an accompanying compromise in well-being. We contend that the annual rates of the rise of the retirement age should be such that the already short (according to the international comparison) duration of economic inactivity is not adjusted down due to the increase in the working life expectancy, which primarily refers to the population at age 50 and above. Decreases in the inactivity period in the context of high mortality rates in Russia may lead to a negative socio-economic effect associated with a reduction in the opportunities for healthcare, performance of family responsibilities, training, and other important functions. This will ultimately be indicative of an increased economic burden placed on a population that does not have a high health and demographic potential.

When interpreting our findings, certain restrictions should be taken into account. We can only show results for synthetic cohorts because we are using cross-sectional data. This means that our results are not directly translated to the experiences of real birth cohorts. They should be used very carefully for any future expectation. Still, our results provide useful information on the developments of economic activity in Russia, on detecting trends and labour force potential. Furthermore, our calculations of working life expectancy were performed by gender, but several other variables important for the labour market outcomes were not accounted for, such as education. Unfortunately, education specific data on life expectancy for Russia is currently only very limitedly available. We calculated the duration of economic inactivity as a whole period, but it includes different states such as education and training, disability retirement and other early retirement, statutory retirement (old-age pension), other (being outside the labour force for other reasons). Having separate estimates instead would be more informative, but this would require more detailed data. These are potentially interesting topics for further study.

\section{Acknowledgement}

The research was supported by the Basic Research Program of the National Research University Higher School of Economics.

\section{References}

Butt, Z., Haberman, S., Verrall, R., \& Wass, V. (2008). Calculating compensation for loss of future earnings: Estimating and using working life expectancy. Journal of the Royal Statistical Society, Series A (Statistics in Society), 171(4), 763-805. doi: 10.1111/j.1467985X.2007.00539.x.

Cambois, E., Robine, J.-M., Brouard, N. (1999). Life expectancies applied to specific statuses. A history of the indicator and the methods of calculation. Population: An English Selection, 11, 7-34.

Denton, F. T., Feaver, C. H., \& Spencer, B. G. (2010). Cohort working life tables for older Canadians. Canadian Studies in Population, 37(1-2), 175-206. 
Dudel, C., Gomez, M. A., Benavides, F. G., \& Myrskylä, M. (2018). The length of working life in Spain: levels, recent trends, and the impact of the financial crisis. European Journal of Population. Retrieved from https://doi.org/10.1007/s10680-017-9458-9.

Dudel, C., \& Myrskylä, M. (2017). Working life expectancy at age 50 in the United States and impact of the Great Recession. Demography, 54, 2101-2123. doi: 10.1007/s13524017-0619-6.

Durand, J. D. (1948). The Labor force in the United States, 1890-1960. New York Social Science Research Council.

Eurostat (2018). Duration of working life - Annual data. Available at http://ec.europa.eu/eurostat/cache/metadata/en/lfsi_dwl_a_esms.htm.

Federal State Statistics Service (2017). Demographic projection to 2035. Retrieved December 19, 2017, from http://www.gks.ru/wps/wcm/connect/rosstat_main/rosstat/ru/ statistics/ population/demography.

Fullerton, Jr. (1972). A new type of working life table for men. Monthly Lab. Rev., 95(7), 2027.

Garfinkle, S. (1963). The length of working life for males, 1900-1960. Manpower Report. №8.

Haberman, S., \& Bloomfeld, D. S. (1990). Work time lost to sickness, unemployment and stoppages: Measurement and application. Journal of the Institute of Actuaries, 117(3), 533-595. doi:10.1017/S0020268100043237.

Hayward, M. D., \& Grady, W. R. (1990). Work and retirement among a cohort of older men in the United States, 1966-1983. Demography, 27(3), 337-356. doi:10.2307/2061372.

Hoem, J. M. (1977). A Markov chain model of working life tables. Scandinavian Actuarial Journal, 1, 1-20.

Human Mortality Database. University of California, Berkeley (USA) \& Max Planck Institute for Demographic Research (Germany). Retrieved from http://www.mortality.org.

Hytti, H., \& Nio, I. (2004). Monitoring the employment strategy and the duration of active working life (Working Paper №38/2004). Helsinki: The Social Insurance Institution. Retrieved from http://hdl.handle.net/10250/3430

Ivanova, M., Balaev, A., \& Gurvich, E. (2017). Povyshenie pensionnogo vozrasta i rynok truda [Increasing in retirement age and the labour market]. Economy Issues, 3, 22-39.

Kruminya, I. (1985). Primenenie tablichnogo metoda pri issledovanii perioda trudovoj deyatel'nosti [The application of the life tables in the study of the period of labour activity]. In: Zvidrin'sh (ed.). Population research. Riga: LGU.

Kudrin, A., \& Gurvich, E. (2012). Starenie naseleniya i ugroza byudzhetnogo krizisa [Population aging and risks of budget crisis]. Economy Issues, 3, 52-79.

Leinonen, T., Martikainen, P., \& Myrskylä, M. (2015). Working life and retirement expectancies at age 50 by social class: Period and cohort trends and projections for Finland. Journals of Gerontology: Series B. Psychological Sciences and Social Sciences, 73(2), 302-313. doi:10.1093/geronb/gbv104.

Liefbroer, A. C., \& Henkens, K. (1999). Labour market careers of successive cohorts of older men in the Netherlands: Changes in age at retirement and in length of working lives. Genus, 55(1/2), 101-119.

Loichinger, E., \& Weber, D. (2016). Trends in working life expectancy in Europe. Journal of Aging and Health, 28(7), 1194-1213. doi: 10.1177/0898264316656509.

Millimet, D. L, Nieswiadomy, M., \& Slottje, D. (2010). Detailed estimation of worklife expectancy for the measurement of human capital: Accounting for marriage and for children. Journal of Economic Surveys, 24(2), 339-361. doi: 10.1111/j.14676419.2009.00618.x. 
Millimet, D. L., Nieswiadomy, M., Ryu, H., \& Slottje, D. (2003). Estimating worklife expectancy: An econometric approach. Journal of Econometrics, 113(1), 83-113. doi: 10.1016/s0304-4076(02)00168-9.

Milovidov, A. (1983). Gody zhizni i gody truda [Years of life and years of work]. M.: Finansy i statistika.

Nurminen, M. M. (2012). Working-life expectancy in Finland: Trends and differentials, 2000-2015. A multistate regression modeling approach. Finnish Centre for Pensions, Reports 03/2012. Retrieved from http://www.etk.fi/publications.

Nurminen, M. M., Heathcote, C. R., Davis, B. A., \& Puza, B. D. (2005). Working life expectancies: The case of Finland 1980-2006. Journal of the Royal Statistical Society: Series A (Statistics in Society), 168(3), 567-581. doi:10.1111/j.1467985X.2005.00364.x.

OECD (2013). Russia: Modernising the Economy. OECD Publishing.

Pervushin, A. (1987). Prodolzhitel'nost' ehkonomicheski aktivnoj zhizni naseleniya SSSR [The duration of the economically active life of the population of the USSR]. Joshchkar-Ola: Marijskij NII.

Preston, S. H., Heuveline, P., \& Guillot, M. (2001). Demography: Measuring and modeling population processes. Oxford: Blackwell Publishing.

Schoen, R., \& Woodrow, K. (1980). Labor force status life tables for the United States, 1972. Demography, 17(3), 297-322. doi: 10.2307/2061105.

Skoog, G. R, \& Ciecka, J. E. (2010). Measuring years of inactivity, years in retirement, time to retirement, and age at retirement within the Markov model. Demography, 47(3), 609628.

Skoog, G. R, \& Ciecka, J. E. (2016). Evolution of worklife expectancy measurement. Forensic Economics, 33-56. doi:10.1057/978-1-137-56392-7_3.

Smith, S. J. (1986). Worklife estimates: Effects of race and education. Washington, US Department of Labor, Bureau of Labor Statistics, Bulletin 2254.

Smith, S. J. (1982). Tables of working life: the increment-decrement model. Washington, US Department of Labor, Bureau of Labor Statistics, Bulletin 2135.

Sullivan, D. F. (1971). A single index of mortality and morbidity. HSMHA Health Report, 86(4), 347-354.

Vishnevsky, A., Vasin, S., \& Ramonov, A. (2012). Vozrast vyhoda na pensiyu i prodolzhitel'nost' zhizni [Retirement age and life expectancy]. Economy Issues, 9, 88109.

Vogler-Ludwig, K. (2009). Monitoring the duration of active working life in the European Union. Final Report. München: Economix Research and Consulting.

Wolfbein, S. L. (1949). The length of working life. Population Studies, 3(3), 286-294.

World Bank (2015). Searching for a new silver age in Russia: The drivers and impacts of population aging. Overview Report. 